\title{
Lymphocyte proliferation activity after limited (Light class) and long (CEI) distance endurance rides in horses
}

\author{
ANNA CYWIŃSKA', EWA SZARSKA ${ }^{2}$, RENATA GÓRECKA ${ }^{3}$, LUCJAN WITKOWSKI ${ }^{3}$, \\ ZUZANNA WYSZYNSSKA', MATEUSZ HECOLD ${ }^{3}$, ANDRZEJ BEREZNOWSKI \\ ANTONI SCHOLLENBERGER ${ }^{l}$, ANNA WINNICKA ${ }^{l}$
}

${ }^{1}$ Department of Pathology and Veterinary Diagnostics, Faculty of Veterinary Medicine, Warsaw University of Life Sciences, Warsaw, Poland ${ }^{2}$ Military Institute of Hygiene and Epidemiology, Warsaw, Poland

${ }^{3}$ Department of Large Animal Diseases with Clinic, Faculty of Veterinary Medicine, Warsaw University of Life Sciences, Warsaw, Poland ${ }^{4}$ Medical Tribune, Warsaw, Poland

\begin{abstract}
Long lasting or high-intensity exercise has been shown to suppress immune response by alterations in the number and functions of leukocytes. Several reports confirmed diminished neutrophil activity in human and equine athletes, but variable results on lymphocyte functions are presented. In this study, we evaluated the mitogen-induced proliferation activity of lymphocyte isolated from horses taking part in endurance competition. Twenty four horses competed on limited distance (Light class) or long distance (CEI) rides were examined. Exercise induced changes in leukocyte number manifested in all horses as neutrophilic leukocytosis and an increase in neutrophil to lymphocyte ratio after both types of rides. Completing limited distance rides did not produced any changes in lymphocyte proliferation activity, but clear alterations in lymphocyte functions have been detected in the horses taking part in long distance rides, even before the start. The reaction to mitogen stimulation in most cases was equal to the activity of unstimulated cells, indicating a kind of unresponsiveness to mitogens. However, the spontaneous activity of the cells was low or high and three patterns of reaction have been shown. It can be concluded, that competing or even preparing to long distance rides may be conductive to alterations in the lymphocyte functions, that can be recognized as immunosuppression. The reaction is highly heterogeneous and seems of limited importance in the evaluation of the suppression of immune response in endurance horses.
\end{abstract}

Key words: horse, endurance, lymphocyte proliferation, exercise-induced immunosuppression.

(Centr Eur J Immunol 2012; 37 (4): 326-331)

\section{Introduction}

Many evidence suggest, that strenuous, high-intensity or long lasting exercise may promote immunosuppression which can lead to increase susceptibility to disease in human and equine athletes [1-7]. This condition is believed to result from alterations in the number and functions of circulating leukocytes. Several reports confirmed the diminished neutrophil function during this period in human and equine athletes $[2,5,7,8]$. However, variable results on the lymphocyte response after exercise have been presented, suggesting that it is highly heterogeneous [8-10].
Functional capacity of lymphocytes is most often evaluated on the basis of their proliferative response upon stimulation with mitogens. The assay represents an in vitro model, which is believed to mimic events that occur after antigen stimulation of lymphocytes in vivo [2, 8-10]. In human many reports have proved that lymphocyte proliferation is changed by exercise, but the response have been seen either elevated, reduced or unchanged [9]. It is generally believed that acute, high-intensity exercise suppresses the activity of lymphocytes. The lymphoproliferative response to mitogens has been reported to decrease in horses 
and ponies exercising on a high-speed treadmill [7, 11-14] and in thoroughbreds after the race [3]. Intense exercise has also been shown to suppress the lymphocyte proliferation response to specific stimulation with equine influenza virus antigens $[12,15]$.

In contrast, no changes in the lymphocyte proliferation activity upon mitogen stimulation were detected after single bout of intense treadmill exercise in unconditioned horses $[13,16]$ and following $1^{\text {st }}$ and $2^{\text {nd }}$ chukkas during polo match [17]. The data mentioned above deal with the short duration, anaerobic exercise of various intense. In horses, much less attention has been given to prolonged aerobic exertion. However, in human a decreased lymphocyte proliferation in response to Phytohemagglutinin (PHA) and Concanavalin A (ConA) stimulation has been reported after marathon run, heavy treadmill exercise and exhausting cycling $[9,18,19]$, but the conclusions cannot be directly applied to horses due to the physiological differences.

We have previously reported, that in horses, the prolonged, extreme endurance exercise (162 km endurance competition) produced the unique pattern of total suppression of lymphocyte reaction to mitogen stimulation [20]. The aim of the present study is to compare the changes in the proliferative response to mitogens of lymphocytes isolated from horses following limited (Light class) and long $\left(\mathrm{CEI} 2 *\right.$ and $\left.\mathrm{CEI} 3^{*}\right)$ distance endurance rides ${ }^{\mathrm{a}}$ and to characterize the pattern of immunosuppression.

\section{Material and methods}

\section{Horses and competition}

Twenty four endurance - trained horses, competed in either limited distance - Light class $(35 \mathrm{~km}$ and $64 \mathrm{~km})$ or long distance - CEI $2 *$ and $3 *$ (championships competitions) endurance rides in Poland were included in this study (Table 1). A star system $(2 *$ and $3 *$ ) rates the CEI rides according to distance (in this case $120 \mathrm{~km}$ and $160 \mathrm{~km}$, respectively) and post-ride recovery rate. Successful completion the distance, all veterinary health checks performed during and following the competition and routine doping control were the inclusion criteria. The owners, Veterinary Commission and the local Ethical Committee agreed to the procedures. The competitions were held in summer (June to September), under similar weather (temperatures $22-24^{\circ} \mathrm{C}$ ) and terrain conditions. All of the horses were dewormed and vaccinated at similar time, did not receive medications or suffer from an infection in the preceding 3 weeks (according to the owner's knowledge). They were housed in similar environment and fed standard diet with adequate mineral and vitamin supplementation. Salt and water were available ad libitum.

\section{Blood samples}

Peripheral blood samples were obtained by jugular venipuncture before (about 6.00 a.m.) and immediately after the competition. Samples were aspirated into a $20 \mathrm{ml}$ syringe, immediately transferred into sterile lithium heparinized tubes for lymphocyte activity studies and into EDTA-3K tubes for haematological tests and kept in $4^{\circ} \mathrm{C}$ until analysis. The total number of leukocytes was counted with an automated hematology analyzer (Abacus), differential counts were determined manually from smears by counting 100 cells and neutrophil to lymphocyte $(\mathrm{N}: \mathrm{L})$ ratio was calculated.

Lymphocytes were isolated by density gradient centrifugation using Histopaque 1077 (Sigma) according to the manufacturers protocol. Briefly, whole blood was layered onto Histopaque 1077 and centrifuged at $400 \mathrm{xg}$ for $30 \mathrm{~min}$ at room temperature. The opaque interface containing lymphocytes was aspirated, washed 3 times in PBS and centrifuged at $150 \mathrm{xg}$ for 10 minutes. Cell viability and cell counts were assessed by trypan blue exclusion.

Table 1. Description of the horses included in the study and distance completion. A star system $\left(2^{*}\right.$ and $\left.3^{*}\right)$ rates the rides according to distance and post-ride recovery rate

\begin{tabular}{lccccr}
\hline Distance $(\mathbf{k m})$ & Number of horses & Age (years) & \multicolumn{2}{c}{ Speed (km/h) } & Time of completion (hours) \\
\hline Light class & 35 & 3 & $5.25 \pm 1.25$ & $10.25 \pm 0.53$ & $3.14 \pm 0.12$ \\
\cline { 2 - 6 } & 64 & 5 & $5.3 \pm 0.3$ & $10.8 \pm 0.53$ & $6.2 \pm 0.3$ \\
\hline CEI $2^{*}$ & 120 & 5 & $8 \pm 0.8$ & $15.69 \pm 1.2$ & $8.11 \pm 0.48$ \\
\hline $3^{*}$ & 160 & 11 & $9.4 \pm 0.6$ & $15.35 \pm 0.6$ & $10.21 \pm 0.51$ \\
\hline
\end{tabular}

\footnotetext{
${ }^{a}$ Light class, CEI $2 *$ and CEI $3 *$ represent the distance and the level of competition. Light class competition are held at the distance below $80 \mathrm{~km}$, with speed limit. CEI (Concours Endurance International) $2 *$ and CEI $3 *$ are the competitions at star levels. A star system is used to rate rides according to the distance and post-ride recovery rate. CEI $2 *-120-139 \mathrm{~km}$ per one day. Recovery to heart rate 64 in 20 minutes on vet gate. CEI $3^{*}-140-160 \mathrm{~km}$ per one day. Recovery to heart rate 64 in 20 minutes on vet gate.
} 


\section{Lymphocyte proliferation assay}

A pellet cells was resuspended in PBS supplemented with $0.1 \%$ bovine serum albumin (BSA, Sigma) to achieve the concentration of $5 \times 10^{7} / \mathrm{ml}$. Then, the cells were labeled with carboxyfluorescein diacetate succinimidyl ester (CFSE, Flu$\mathrm{ka}$ ), added to the cells at $10 \mu \mathrm{M}$ concentration. The reaction was performed for 10 minutes, at $37^{\circ} \mathrm{C}$, in the dark. The labeling was quenched by adding $5 \mathrm{ml}$ ice-cold RPMI1640/2 mM glutamine $/ 10 \%$ FCS and incubating $5 \mathrm{~min}$ on ice. Then, the cells were washed 3 times in culture medium (Sigma) containing: RPMI1640 without phenol red, $2 \mathrm{mM}$ glutamine, $10 \%$ FCS and Antibiotic Antimycotic Solution and resuspended to a final concentration of $5 \times 10^{5}$ cells $/ \mathrm{ml}$. Each sample, unstimulated cells or the cells stimulated with mitogens was tested in quadruplicate, in flat-bottom 96-well plates ( $200 \mu 1 /$ well). Phytohemagglutinin (PHA, Sigma) and Concanavalin A (ConA, Sigma) in previously determined optimal concentrations $(2 \mu \mathrm{g} / \mathrm{ml})$ were used for the stimulation. Cells were incubated in $5 \% \mathrm{CO}_{2}$ environment, at $37^{\circ} \mathrm{C}$ for 72 hours. Labeled cells were then analyzed by flow cytometry (FACSCalibur, Becton Dickinson). Linear histograms of fluorescence intensity (FL1) were obtained by using CELL Quest software (Becton Dickinson) and posed the basis to determine the percentage of the cells undergoing divisions. The percentage of proliferating cells has been recorded and the rate of cell death has been evaluated according to the method described previously [10]. Proliferation index (PI) was calculated as the percentage of cell division in the sample stimulated with mitogen divided by the percentage of cell division in unstimulated sample at the same time.

\section{Statistical analysis}

Statistical procedures, means and standard errors of mean were computed using the STATISTICA 6.0 for Windows. Results are expressed as means \pm standard errors of mean (SEM). The results before and after the rides were compared with Wilcoxon signed rank test. Statistical comparisons between the horses participating in Light class and CEI competitions were made using Mann-Whitney $U$ test; $p \leq 0.05$ was considered significant.

\section{Results}

All haematological parameters (Table 2) determined in the horses before the competition, regardless the distance varied within normal ranges for equine species [21]. After both, Light class and CEI rides, WBC, neutrophil numbers and $\mathrm{N}$ : L ratio increased significantly $(p \leq 0.05)$. Following long distance (CEI) rides WBC and neutrophil numbers even exceeded reference values. The numbers of lymphocytes were close to or slightly below (in 2 cases) the lower limit of normal ranges.

Proliferation indices after both PHA and ConA stimulations before and following the rides differed significantly $(p \leq 0.001)$ between the groups of horses taking part in Light class and CEI competitions (Table 2). In both groups, large differences among individuals were noted.

Lymphocytes isolated from the horses participating in Light class rides before and after competition responded to mitogen stimulation (Fig. 1) similarly, without significant differences in the group.

Table 2. Leukogram parameters and proliferation indices in the horses before and after limited distance (L class) and long distance $(\mathrm{CEI})$ rides

\begin{tabular}{|c|c|c|c|c|}
\hline \multirow[t]{2}{*}{ Parameter } & \multicolumn{2}{|c|}{ Limited distance (L CLASS) rides } & \multicolumn{2}{|c|}{ Long distance (CEI) rides } \\
\hline & Before & After & Before & After \\
\hline WBC $\left[\times 10^{9} / 1\right]$ & $7.48 \pm 0.41$ & $13.9 \pm 1.6^{\mathrm{a} *}$ & $9.8 \pm 1.13$ & $18.76 \pm 1.72^{\mathrm{a} *}$ \\
\hline Neutrophils $\left[\times 10^{9} / 1\right]$ & $5.74 \pm 0.28$ & $12.06 \pm 0.45^{\mathrm{a} *}$ & $6.88 \pm 0.77$ & $16.76 \pm 1.7^{\mathrm{a} *}$ \\
\hline Lymphocytes $\left[\times 10^{9} / 1\right]$ & $2.03 \pm 0.27$ & $1.8 \pm 0.56$ & $1.64 \pm 0.39$ & $1.3 \pm 0.2$ \\
\hline Eosinophils $\left[\times 10^{9} / 1\right]$ & $0.20 \pm 0.04$ & $0.15 \pm 0.1$ & $0.27 \pm 0.1$ & $0.11 \pm 0.09$ \\
\hline Basophils $\left[\times 10^{9} / 1\right]$ & $0.03 \pm 0.01$ & $0.01 \pm 0.01$ & 0 & 0 \\
\hline Monocytes $\left[\times 10^{9} / 1\right]$ & $0.02 \pm 0.01$ & $0.01 \pm 0.01$ & $0.01 \pm 0.01$ & $0.01 \pm 0.01$ \\
\hline $\mathrm{N}: \mathrm{L}$ & $2.82 \pm 0.42$ & $6.7 \pm 0.55^{\mathrm{a} *}$ & $3.54 \pm 0.58$ & $12.46 \pm 1.8^{\mathrm{a} *}$ \\
\hline $\begin{array}{l}\text { Proliferation index } \\
\text { after PHA stimulation }\end{array}$ & $4.68 \pm 0.44$ & $5.41 \pm 0.62$ & $1.23 \pm 0.09^{* * *}$ & $1.11 \pm 0.11 * * *$ \\
\hline $\begin{array}{l}\text { Proliferation index } \\
\text { after ConA stimulation }\end{array}$ & $6.47 \pm 0.49$ & $6.59 \pm 0.68$ & $1.41 \pm 0.09^{* * *}$ & $1.27 \pm 0.14 * * *$ \\
\hline
\end{tabular}

*statistically significant difference; $p \leq 0.05$, between the horses taking part in limited and long distance rides

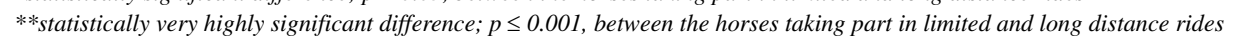

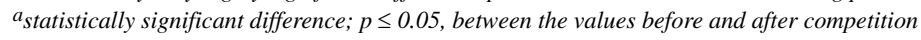


A

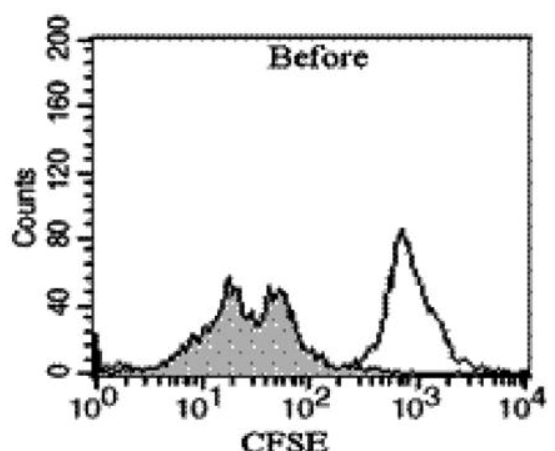

B

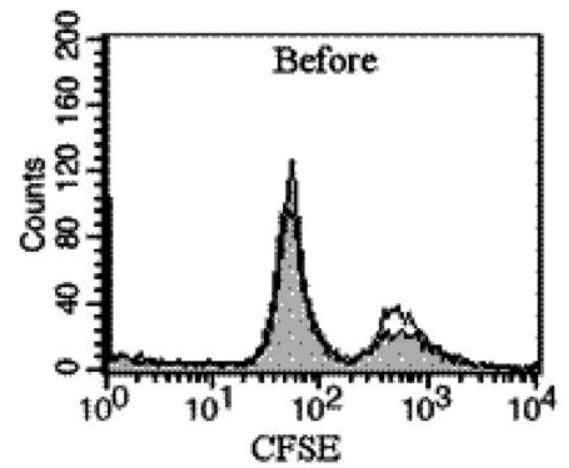

C

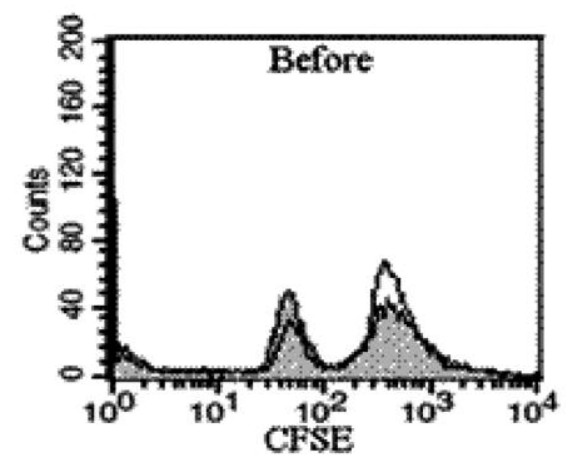

$\mathrm{D}$

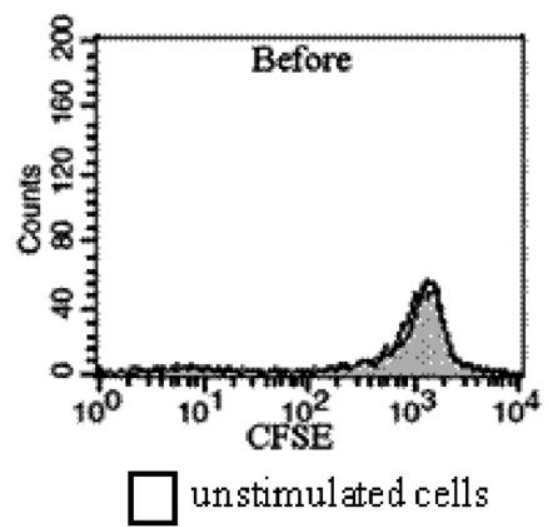

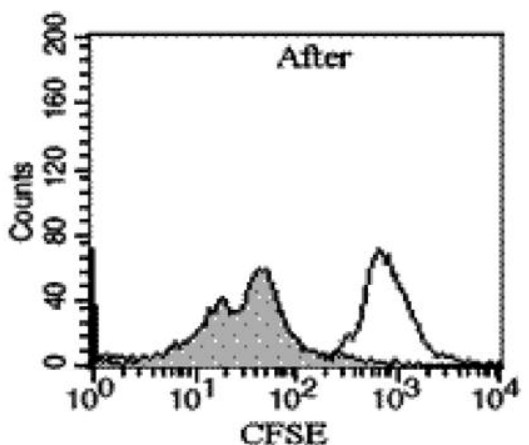
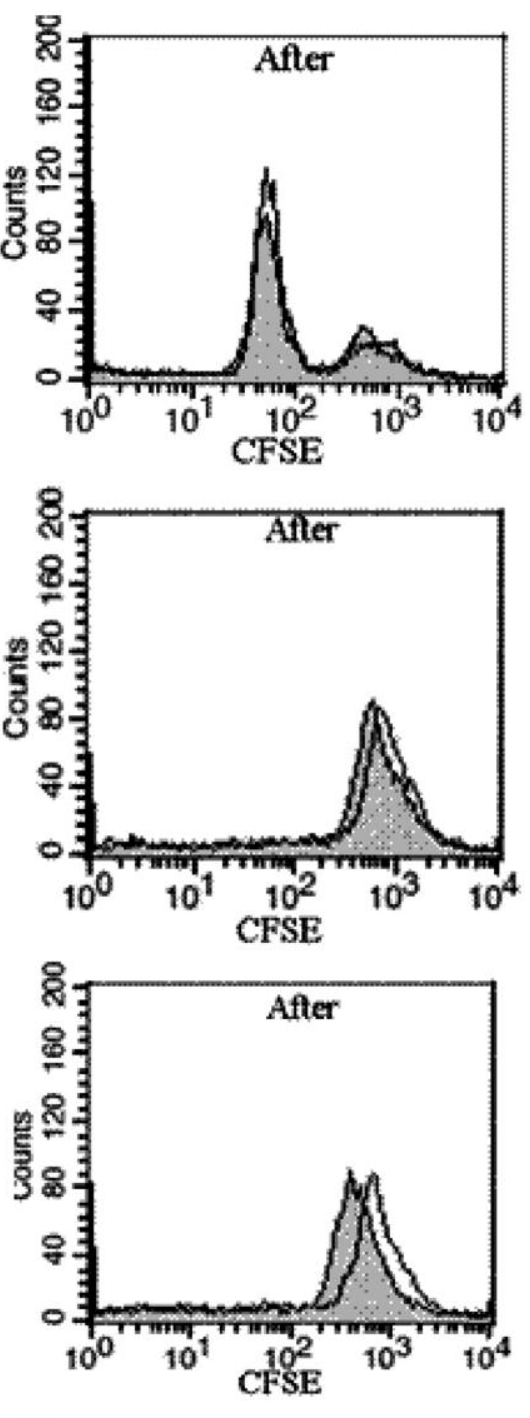

after ConA stimulation

Fig. 1. Patterns of lymphocyte response to mitogen stimulation in the horses before and after the rides. (A) Lymphocytes isolated from the horses taking part in limited distance (Light class) rides; low spontaneous activity of the cells and similar response to stimulation before and after the ride. (B-D) Lymphocytes isolated from the horses taking part in long distance (CEI) rides. (B) High spontaneous activity of the cells and lack of the response to mitogens before and after the rides. (C) High spontaneous activity of the cells and lack of the response to mitogens before the ride and low spontaneous activity of the cells and lack of the response to mitogens after the ride. (D) Low spontaneous activity of the cells and lack of the response to mitogens before and after the rides 
In the horses participating in CEI rides the proliferation indices were low and similar in all cases, but three patterns of reactions (Fig. 1) were determined:

- in 8 horses the activity of unstimulated cells was high ( $30 \%$ to $72 \%$ ) before and after the rides and the responses to mitogens were similar ( $30 \%$ to $82 \%$ ),

- in 4 horses the activity of unstimulated cells and the responses to mitogens were high before the rides (20\% to $40 \%$ ) but after the rides both, the activity of unstimulated cells and the response to mitogens were low (2\% to 5\%), - in 4 horses the activity of unstimulated cells was low (4\% to $9 \%$ ) before and after the rides and the responses to mitogens were similar (6\% to $9 \%)$.

In all cases, regardless of the patterns of the reactions, the calculated proliferation indices before and after the rides were about 1 .

\section{Discussion}

It is usually concluded, that the immune response is suppressed following exhausting exertion. Maximal exercise in unconditioned horses is even an established model for inducing immunosuppression [14]. This condition is defined by changes in leukocyte numbers and activities and is believed to increase with exercise intensity and duration $[8$, 9]. In our study exercise-induced changes in leukocyte numbers manifested as neutrophilic leukocytosis resulting in an increase in $\mathrm{N}: \mathrm{L}$ ration after both: limited distance (Light class) and long distance (CEI) rides. This kind of changes is known as stress leukogram and has been widely reported after intensive or prolonged exertion [5, 7, 16, 20, 22]. In endurance exercise, the changes result from biphasic, catecholamine and cortisol dependent process [7, 22].

The presence of stress leukogram proved, that both Light class and CEI rides posed the exertion intense enough to affect leukocyte status. However, only long distance (CEI) endurance rides promoted the alterations in lymphocyte functions. After limited distance (Light class) rides, the lymphocyte proliferation activity was similar to the results obtained before the ride. The proliferation indices have shown, that the percentage of cells responding to mitogens was five-sixfold higher, then the percentage of the cells that proliferated spontaneously. These indices are hard to compare with the results obtained by other authors in horses, because they usually used the method with thymidine incorporation. Thus, the exercise effect on lymphoproliferative response has been documented as changed thymidine uptake (expressed as counts per minute) after stimulation with mitogens [14] or stimulation indices calculated various ways, by subtracting or dividing the values obtained in stimulated and unstimulated cells. For example, Wong et al. [16] calculated net stimulation (NS), expressed in counts per minute (cpm); but Nesse et al. [3] calculated stimulation index and expressed it in percentage. The method we chose gives possibilities to interpret the results more accu- rate. Using the same method, Green and Rowbottom [10] have shown that in human, treadmill exercise to volitional exhaustion resulted in decrease in cell expansion rate due to an increase in cell death, but not mitosis rate. In our study, the calculation used by Green and Rowbottom [10] did not indicate the notable cell death neither in case of limited nor long distance rides.

Before and after long distance (CEI) rides, the proliferation indices were close to 1 , indicating that the reaction to mitogens was almost equal to spontaneous proliferation activity. However, three patterns of this reaction occurred. In 4 horses, the activity of both, unstimulated and stimulated cells was low, similar to the activity of unstimulated cells in the horses taking part in Light class rides. In 8 horses, the spontaneous activity was high, similar to the activity observed after mitogen stimulation in the horses taking part in limited distance rides. In 4 horses, the activity of stimulated and unstimulated cells was high before the ride but low after the ride. This fact indicates a kind of anergy to mitogens. In case of high activity of unstimulated cells, it can be postulated, that the cells were strongly stimulated before isolation and further in vitro stimulation did not increase their activity. This fact may have resulted from a kind of refraction state, or cell activity simply reached maximal level before adding mitogens. Low activity of the cells can be explained as abnormalities in signal transduction pathways or cell metabolism insufficient for proliferation.

Any exercise-induced changes in lymphocyte proliferation activities are generally explained by neuroendocrine mechanisms. Stress hormones, including catecholamines and particularly cortisol are discussed most often $[3,7,8$, $18,23]$. However, the process is multifactorial and may be affected also by other hormones including growth hormone and insulin, but also cytokines, growth factors, aminoacids, glucose, vitamins and oxidant/antioxidant balance $[4,7,8$, $19,24,25]$. In short lasting or single bout of exercise, the differences in cortisol levels are noticeable [3]. Long distance rides last for whole of day, so that interpretation is much more difficult because it may vary during the ride due to events on the route, veterinary checks and even the diurnal fluctuations. Similarly, variations in glucose level are obvious during whole day competition.

We have previously reported one of these pattern of suppression in endurance horses, but a week before the competition it was not detected [20]. This fact suggests that the factors affecting lymphocyte proliferation occur rather during final preparation to the competition. However, four horses expressed different lymphocyte activity before and after the ride, thus both: final preparation and the competition pose a risk of suppression of lymphocyte activity. The clinical relevance of this finding is hard to interpret. The cells that do not respond to mitogens probably do not respond also to antigen stimulation and are not able to provide a protective immune response. On the other hand, it is generally believed, that the effect of exercise on lymphocyte activ- 
ity effect is transient [8]. Lunn et al. [14] have shown, that administration of MLV vaccine to ponies with exerciseinduces immunosuppression is safe and effective, but Folsom et al. [15] demonstrated, that exercise-induced immunosuppression increased the susceptibility to influenza.

In conclusion, we have determined, that limited distance (Light class) rides did not have any impact on lymphocyte proliferation activity, but long distance (CEI $2 *$ and $3 *$ ) rides and even the final phase of preparation to the competition promote alterations, which may be recognized as immunosuppression. However, the pattern of lymphocyte proliferation activity is heterogenous and likely to be promoted by various factors, so it seems of limited value in the functional evaluation of exercise-induced immunosuppression in endurance horses.

The study was supported by the State Committee for Scientific Research, Poland (grant no N N308 577139 for Anna Winnicka).

\section{References}

1. Burrell MH, Wood JL, Whitwell KE, et al. (1996): Respiratory disease in thoroughbred horses in training: the relationships between disease and viruses, bacteria and environment. Vet Rec 139: 308-313.

2. Nieman DC (1997): Risk of upper respiratory tract infection in athletes: an epidemiologic and immunologic perspective. J Athl Train 32: 344-349.

3. Nesse LL, Johansen GI, Blom AK (2002): Effects of racing on lymphocyte proliferation in horses. Am J Vet Res 63: 528530

4. Pedersen BK, Toft AD (2000): Effects of exercise on lymphocytes and cytokines. Br J Sports Med 34: 246-251.

5. Robson PJ, Alston TD, Myburgh KH (2003): Prolonged suppression of the innate immune system in the horse following an $80 \mathrm{~km}$ endurance race. Equine Vet J 35: 133-137.

6. Wood JL, Newton JR, Chanter N, Mumford JA (2005): Association between respiratory disease and bacterial and viral infections in British racehorses. J Clin Microbiol 43: 120-126.

7. Krumrych W (2011): Wpływ wysiłku fizycznego na mechanizmy odpornościowe u koni. Medycyna Wet 67: 177-180.

8. Hines MT, Schott HC 2nd, Bayly WM, Leroux AJ (1996): Exercise and immunity: a review with emphasis on the horse. J Vet Intern Med 10: 280-289.

9. Nielsen HB, Pedersen BK (1997): Lymphocyte proliferation in response to exercise. Eur J Appl Physiol Occup Physiol 75: 375-379.

10. Green KJ, Rowbottom DG (2003): Exercise-induced changes to in vitro T-lymphocyte mitogen responses using CFSE. J Appl Physiol 95: 57-63.

11. Kurcz EV, Lawrence LM, Kelley KW, et al. (1988): The effect of intense exercise on the cell-mediated immune response of horses. J Equine Vet Sci 8: 237-239.

12. Keadle TL, Pourciau SS, Melrose PA, et al. (1993): Acute exercise stress modulates immune function in unfit horses. J Equine Vet Sci 13: 226-231.

13. Horohov DW, Dimock A, Guirnalda P, et al. (1999): Effect of exercise on the immune response of young and old horses. Am J Vet Res 60: 643-647.
14. Lunn DP, Hussey S, Sebing R, et al. (2001): Safety, efficacy, and immunogenicity of a modified-live equine influenza virus vaccine in ponies after induction of exercise-induced immunosuppression. J Am Vet Med Assoc 218: 900-906.

15. Folsom RW, Littlefield-Chabaud MA, French DD, et al. (2001): Exercise alters the immune response to equine influenza virus and increases susceptibility to infection. Equine Vet $\mathrm{J}$ 33: 664-669.

16. Wong CW, Smith SE, Thong YH, et al. (1992): Effects of exercise stress on various immune functions in horses. Am J Vet Res 53: 1414-1417.

17. Malinowski K, Potter JT, Dinger JE (1993): Temporal variation and effects of exercise on lymphocyte proliferative response to phytohemagglutinin in polo ponies. In: Proceedings of Thirteenth Equine Nutrition and Physiology Society Symposium, pp. 221-222

18. Tvede N, Kappel M, Klarlund K, et al. (1994): Evidence that the effect of bicycle exercise on blond mononuclear cell proliferative responses and subsets is mediated by epinephrine. Int J Sports Med 15: 100-104.

19. Henson DA, Nieman DC, Pistilli EE, et al. (2004): Influence of carbohydrate and age on lymphocyte function following a marathon. Int J Sport Nutr Exerc Metab 14: 308-322.

20. Cywińska A, Wyszyńska Z, Górecka R, et al. (2010): The effect of the $162 \mathrm{~km}$ endurance ride on equine peripheral blood neutrophil and lymphocyte functions. Pol J Vet Sci 13: 279-285.

21. Smith BP (2009): Large animal internal medicine. 4th ed. Mosby Inc., St. Louis, Missouri.

22. Korhonen PA, Lilius EM, Hyyppä S, et al. (2000): Production of reactive oxygen species in neutrophils after repeated bouts of exercise in standardbred trotters. J Vet Med A Physiol Pathol Clin Med 47: 565-573.

23. Malinowski K, Shock EJ, Rochelle P, et al. (2006): Plasma beta-endorphin, cortisol and immune responses to acute exercise are altered by age and exercise training in horses. Equine Vet J Suppl 36: 267-273.

24. De la Fuente M, Victor VM (2000): Anti-oxidants as modulators of immune function. Immunol Cell Biol 78: 49-54.

25. Fox CJ, Hammerman PS, Thompson CB (2005): Fuel feeds function: energy metabolism and the T-cell response. Nat Rev Immunol 5: 844-852. 